thought to be essentially that which issues in action and is thereby put to the test; but he avoids the errors that come from despising reflective thought and from taking a commercial view of the ends of action. His statement (p. 22) that the full development of mental process requires all three phases, cognitive, rsthetic and practical, could scarcely be bettered. If this exposition could be taken as a preliminary sketch and the classification of philosophies as schematic and limited to the purpose of defining his own view, there would be nothing to find fault with. But apparently it is intended to be complete. Other types of opposition in thought, excluded from the classification, are dismissed as unimportant, ingeniously but not convincingly. The classification covers best those recent minor thinkers who fit readily into 'schools', but scarcely any of the great thinkers. The Greeks do not fit in ; nor do Descartes, Spinoza or Kant. Excessive use is made of the ambiguity of the terms 'idealism' and 'materialism'. The notion of progress as change in any determinate direction is turned too easily into that of change which meets with our moral approval. Lastly, there seems no reason why those who recognize the importance of temporal process or progress in any sense should agree on anything else. There is as much difference between Herbert Spencer, Bergson and Prof. Sheldon as between any three philosophers taken at random.

A. D. RITCHIE.

\section{THE ANIMAL IN HEALTH}

\section{Physiology of Farm Animals}

By Dr. F. H. A. Marshall and E. T. Halnan. Third edition. Pp. xi+340. (Cambridge: At the University Press, 1945.) 18s. net.

WTHLE most text-books on animal physiology are written from the point of view of the treatment of diseased conditions, this book by Marshall and Halnan is exceptional in that its object is the teaching of physiology as a basis for the management of the animal for production, normal health and growth. Animal physiology forms the fundamental science on which the teaching in the breeding, feeding and management of farm animals should be based. In the past, teaching in this sphere has been almost entirely based on practical animal husbandry rather than on the basal science. The science of animal physiology should in the future stand in the same relation to animal production as the science of botany has in the past stood as a basis for teaching in crop production in agricultural colleges. With the increasing demand for knowledge in the field of applied science and with the present emphasis on the livestock side of British agriculture, the new edition of this book, which has been out of print for some time, should supply a need for agricultural students and others interested in farm animals.

Naturally the functions of nutrition, reproduction including milk secretion, growth and locomotion find a larger place than in most text-books of physiology. In this respect it more nearly resembles the textbooks of physiology of some sixty years ago. The present edition has been thoroughly revised and includes the results of recent investigations, particularly in the fields of nutrition and reproduction. The chapters on the energy requirements of the body, metabolism of organic and ash constituents, and feeding standards include much useful information on the results of modern research and are presented in a clear and simple form. A chapter on digestion and other facts concerning the fowl, so frequently neglected in modern books on physiology, is included. Similarly, the chapters on the male generative organs, the female generative organs including the mammary gland, and growth give the essential facts elucidated by recent research in a form which can easily be grasped by the student.

In detailing these results the research worker's name is given, but one misses, however, a short list of references to outstanding papers, books and reviews of the subject, which would enable the reader to continue with advanced study in any particular aspect in which he might be interested. The large number of illustrations makes the book particularly suitable as an introduction to the subject for the agricultural and veterinary student. JоHN HAMMOND.

\section{A TEXT-BOOK OF HEAT}

\section{A Text-Book of Heat}

By G. R. Noakes. Pp. viii +469 . (London: Macmillan and Co., Ltd., 1945.) 10s. 6d.

$7 \mathrm{O}$ his successful volumes on optics and on electricity and magnetism, Mr. Noakes now adds a comprehensive text-book on heat "up to scholarship standard". Instead of taking the material of the older books, correcting obvious errors and including new matter merely with the object of securing encyclopædic completeness, he has wisely chosen the more philosophic plan of examining critically current ideas on the subject, in order to present them in such a way that the young physicist may receive a sure grounding in fundamentals rather than make an acquaintance with an excessive range of isolated facts and opinions.

Guided by his wide teaching experience, the author has deemed it necessary to challenge much that has become almost sacrosanct by dint of uncritical repetition in the past. Thus, definitions have been examined and often found wanting in precision; $\theta x-$ perimental results have been reviewed as to their meaning and application and, with characteristic and commendable boldness, old and inaccurate methods of measurement (the only claim of which to value was the doubtful one of respect for teaching traditions) have been omitted or relegated to a mere note in favour of up-to-date working practice hitherto scarcely touched upon in text-books of this standard.

The treatment throughout is highly original and stimulating. Physics teachers will take special delight in the presentation of thermometry, calorimetry, kinetic theory of gases, transference of heat and thermodynamics. The chapters on low temperatures and heat processes in the atmosphere provide a valuable survey of recent research in fields that have become of great importance to everyday life; indeed the realistic outlook of the whole volume, coupled with its sound statement of fundamental principles, would seem to render it a fitting guide to the 'heat' section of the course for the new National Certificates in Applied Physics, and to this end it may be strongly recommended to technical teachers.

Practising physicists who desire a refresher course in classical physies will find the volume both entertaining and instructive, especially if they attempt some of the searching numerical examples provided for exercise. 